\title{
Risk factors for adverse outcomes in vaginal preterm breech labor
}

\author{
Anna Toijonen ${ }^{1}\left[\right.$. Seppo Heinonen ${ }^{1} \cdot$ Mika Gissler $^{2} \cdot$ Georg Macharey ${ }^{1}$
}

Received: 7 May 2020 / Accepted: 28 July 2020 / Published online: 7 August 2020

(c) The Author(s) 2020

\begin{abstract}
Purpose To assess the risk factors for adverse outcomes in attempted vaginal preterm breech deliveries.

Methods A retrospective case-control study, including 2312 preterm breech deliveries ( $24+0$ to $36+6$ gestational weeks) from 2004 to 2018 in Finland. The preterm breech fetuses with adverse outcomes born vaginally or by emergency cesarean section were compared with the fetuses without adverse outcomes with the same gestational age. A multivariable logistic regression analysis was used to calculate the risk factors for adverse outcomes (umbilical arterial pH below 7, 5-min Apgar score below 4, intrapartum stillbirth and neonatal death $<28$ days of age).

Results Adverse outcome in vaginal preterm breech delivery was associated with maternal obesity (aOR 32.19, CI 2.97348.65), smoking (aOR 2.29, CI 1.12-4.72), congenital anomalies (aOR 4.50, 1.56-12.96), preterm premature rupture of membranes (aOR 1.87, CI 1.00-3.49), oligohydramnios (28-32 weeks of gestation: aOR 6.50, CI 2.00-21.11, 33-36 weeks of gestation: aOR 19.06, CI 7.15-50.85), epidural anesthesia in vaginal birth (aOR 2.44, CI 1.19-5.01), and fetal growth below the second standard deviation (28-32 weeks of gestation: aOR 5.89, CI 1.00-34.74, 33-36 weeks of gestation: aOR 12.27, CI 2.81-53.66).

Conclusion The study shows that for each subcategory of preterm birth, there are different risk factors for adverse neonatal outcomes in planned vaginal breech delivery. Due to the extraordinary increased risk of adverse outcomes, we would recommend a planned cesarean section in very preterm breech presentation $(28+0$ to $32+6$ weeks) with severe maternal obesity, oligohydramnios, or fetal growth restriction and in moderate to late preterm breech presentation $(33+0$ to $36+6$ weeks) with oligohydramnios or fetal growth restriction.
\end{abstract}

Keywords Preterm delivery $\cdot$ Preterm labor $\cdot$ Breech presentation $\cdot$ Vaginal labor $\cdot$ Risk factor $\cdot$ Adverse outcome

Abbreviations
$\begin{array}{ll}\text { ICD-10 } & \begin{array}{l}\text { International Statistical Classification of } \\ \text { Diseases and Related Health Problems 10th } \\ \text { Revision }\end{array} \\ \text { BMI } & \text { Body mass index }\end{array}$

Anna Toijonen

anna.toijonen@hus.fi; anna.toijonen@gmail.com

Seppo Heinonen

seppo.heinonen@hus.fi

Mika Gissler

mika.gissler@thl.fi

Georg Macharey

georg.macharey@hus.fi

1 Department of Obstetrics and Gynecology, University Hospital (HUS), University of Helsinki, Haartmaninkatu 2, 00290 Helsinki, Finland

2 National Institute for Health and Welfare (THL), Helsinki, Finland
PPROM Preterm premature rupture of membranes

SD The second standard deviation

WHO World Health Organization

OR Crude odds ratio

$\mathrm{Cl}$ Confidence interval

aOR Adjusted odds ratio

\section{Introduction}

Around $4 \%$ of all fetuses are in breech presentation at birth $[1,2]$. In preterm labor breech presentation is more common than in term and every fourth of all fetuses born extremely preterm are in breech presentation at birth [3-6]. Breech presentation in preterm and term pregnancies is associated with obstetric risk factors for adverse neonatal outcomes, such as oligohydramnios, fetal growth restriction, and congenital anomalies [7-9]. Vaginal breech delivery at term is a risk factor for short-term neonatal morbidity [10], and 
therefore, vaginal breech delivery is feasible only for wellselected patients [11-15]. In vaginal preterm breech delivery, the situation is still unclear in which cases a vaginal delivery is associated with an increased adverse neonatal outcome. The royal college of obstetricians and gynaecologists stated in their breech delivery guidelines that a spontaneous vaginal breech labor in preterm pregnancies is not contraindicated if an immediate cesarean delivery is not needed for maternal or fetal reasons [16]. In many countries, cesarean section is the most common way of delivery for preterm breech fetuses as several studies have suggested that preterm breech fetuses delivered by a primary cesarean section have a significantly lower risk of neonatal mortality compared with those delivered vaginally [17-19]. Cochrane review 2013 could not recommend the mode of birth instead of another in preterm deliveries irrespectively of fetal presentation [20].

Earlier studies were able to identify risk factors for adverse neonatal outcome in vaginal term breech deliveries $[8,11,21]$, but there is no research available regarding risk factors for adverse neonatal outcome in vaginal preterm breech delivery. Our study aims to identify risk factors for adverse neonatal outcomes in vaginal preterm delivery. This information is needed, since every tenth baby is born preterm [20] and many of them are in a breech position. Obstetricians need adequate information to identify those women who should give birth by cesarean section in any case.

\section{Materials and methods}

The study is a population-based case-control study, including all singleton breech deliveries from 24 to 36 completed weeks of gestation that were delivered vaginally or by emergency cesarean section in Finland. The study period ranged from January 1st, 2004 to December 31st, 2018. The population included altogether 2312 preterm breech deliveries.

We utilized the data of the national medical birth register and the hospital discharge register maintained by the Finnish Institute for Health and Welfare. The authorization to use the data was obtained from the Finnish Institute for Health and Welfare as required by the national data protection law in Finland (reference number THL/652/5.05.00/2017). All maternity hospitals are obligated to report clinical data on national registers. The national medical birth register includes all live births and stillbirths from 22 weeks or from 500 grams. The hospital discharge register contains information on all inpatient and outpatient care in public hospitals including data from maternal, obstetric, and neonatal care. International Statistical Classification of Diseases and Related Health Problems 10th Revision, ICD-10, is used to code the information.
We limited the study population to the fetuses born vaginally or by emergency cesarean section, as we wanted to research intrapartum risk factors of preterm breech deliveries. We excluded multiple gestations, antepartum stillbirths, deliveries before 24 weeks of gestation, and term pregnancies from our study. The deliveries complicated with uterus rupture (ICD-10 O71.0, O71.1), placental abruption, and severe congenital anomalies such as chromosomal and heart defects diagnosed at birth hospital (ICD-10 Q90-Q99, Q20, Q22, Q28) that might have affected on the newborns surviving, were excluded from the study.

The primary outcome of the study was an adverse outcome defined as the following: umbilical arterial $\mathrm{pH}$ below 7, a 5-min Apgar score below 4, intrapartum stillbirth or neonatal death between 0 and 27 days of age. The following maternal variables were included in the analysis: age, parity, pre-pregnancy body mass index (BMI), smoking, in vitro fertilization, history of cesarean section, and maternal hypoor hyperthyroidism (ICD-10 E03, E05). The obstetric risk factors assessed in the analysis were: maternal gestational diabetes (ICD-10 O24.4) and other diabetes treated with insulin (ICD-10 O24.0), arterial high blood pressure or preeclampsia (ICD-10 O13, O14), oligohydramnios (ICD$10 \mathrm{O} 41.0$ ), and preterm premature rupture of membranes (PPROM) (ICD-10 O42). Induction of labor and the use of epidural anesthesia during labor were also included in the variables. The fetal factors such as sex, fetal birthweight below the second standard deviation (SD), and congenital fetal anomalies, as defined in the register of congenital malformations, were included in the analysis.

We divided the study population into three groups according to the World Health Organization (WHO) definitions of preterm deliveries. A fetus born alive before 37 completed weeks of pregnancy is defined as preterm birth, according to WHO. WHOs recommended subcategories based on gestational age were used in the division of the groups: extremely preterm (less than 28 pregnancy weeks), very preterm ( 28 to 32 pregnancy weeks), and moderate to late preterm (32 to 37 pregnancy weeks).

The preterm breech fetuses with adverse outcomes were compared with the fetuses without adverse outcomes with the same gestational age. Each study group, divided according to WHO classification, was separately adjusted.

We used SPSS for 19 to perform the statistical analyses. The adjustments with a binary logistic regression model were calculated for the study population. A Chi squared test or Fisher's exact test was used when appropriate. Odds ratio (ORs) and corresponding 95\% confidence interval (CIs) for each risk factor for adverse outcomes were calculated, and $p$ values below $\leq 0.05$ were considered statistically significant. 


\section{Results}

Our study included 2312 singleton preterm breech deliveries born between $24+0$ and $36+6$ gestational weeks in 2004-2018 in Finland. Out of these deliveries, 7.4\% (172 fetuses) had adverse outcomes. The risk of having adverse outcomes was over tenfold in the fetuses born in $24+0$ to $27+6$ weeks of gestation and threefold in $28+0$ to $32+6$ weeks of gestation, compared to the late preterm breech deliveries (Fig. 1).

In 24 to 28 weeks of gestational age, 78 out of 250 breech deliveries $(31.2 \%)$ had an adverse outcome. In these gestational weeks, the only significant risk factor in a trial of vaginal breech labor emerging from our study was PPROM (aOR 1.87, CI 1.00-3.49) (Table 1).

Among very preterm breech deliveries $(28+0$ to $32+6$ weeks of gestation), nearly one out of ten fetuses $(47 / 518,9.1 \%)$ had adverse outcomes. Severe maternal obesity (aOR 32.19, CI 2.97-348.65), oligohydramnios (aOR 6.50, CI 2.00-21.11), congenital anomalies (aOR $4.50,1.56-12.96$ ), and fetal growth restriction (aOR 5.89, CI 1.00-34.74) increased the risks for adverse outcomes in these gestational weeks. Nulliparity (aOR 0.43 , CI 0.18-0.99) and maternal preeclampsia or high blood pressure (aOR 0.21, CI 0.05-0.96) were associated with a decreased risk of adverse outcome (Table 2).

In late preterm deliveries, the adverse outcomes became less frequent, as in 33 to 36 gestational weeks, only 47 out of 1544 deliveries (3.0\%) had an adverse outcome.
Significant risk factors for adverse outcomes in late preterm breech deliveries in our study were maternal smoking (aOR 2.29, CI 1.12-4.72), oligohydramnios (aOR 19.06, CI 7.15-50.85), epidural anesthesia in vaginal birth (aOR 2.44, CI 1.19-5.01), and fetal growth restriction (aOR 12.27, CI 2.81-53.66) (Table 3).

\section{Discussion}

Our study shows that for each subcategory of preterm birth, there are different risk factors for adverse neonatal outcomes in planned vaginal preterm breech delivery. In extremely preterm breech deliveries $(24+0$ to $27+6$ weeks) PPROM was associated with adverse neonatal outcomes. In very preterm breech deliveries ( $28+0$ to $32+6$ weeks) severe maternal obesity, oligohydramnios, congenital anomalies, and fetal growth restriction were associated with a higher risk of adverse neonatal outcome. In moderate to late preterm breech deliveries $(33+0$ to $36+6$ weeks) maternal smoking, oligohydramnios, epidural anesthesia, and fetal growth restriction were identified as risk factors.

Oligohydramnios was found to increase the adverse outcomes 6.5 -fold for very preterm and 19 -fold for moderate to late preterm breech deliveries in our study. The results are supported by the previous literature that has shown oligohydramnios to be a risk factor for adverse perinatal outcomes in term breech pregnancies [8]. Oligohydramnios is linked to diminished fetal movements, compression of the umbilical cord, insufficiency of the placental as well as fetal

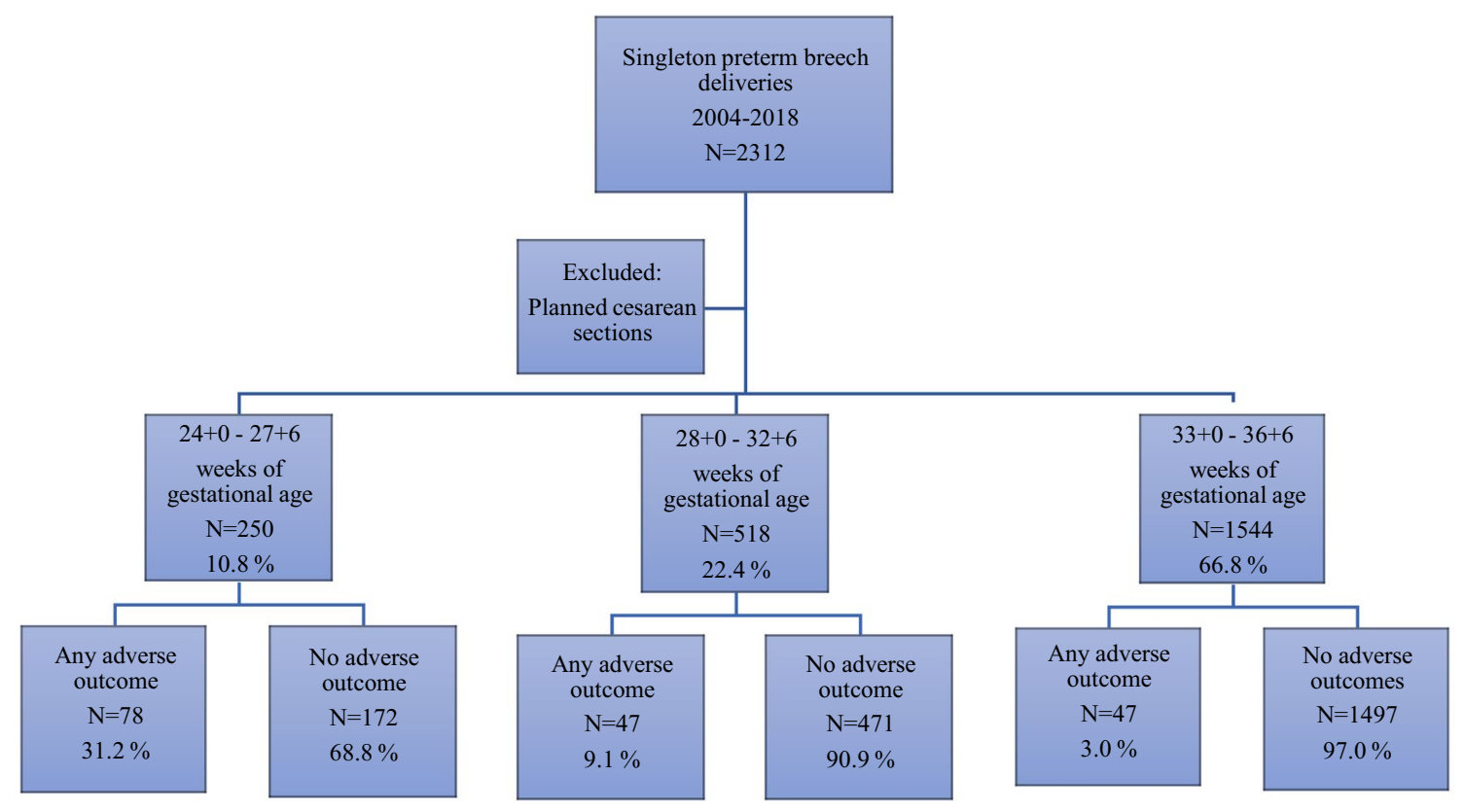

Fig. 1 Breech presentation and adverse outcomes during the period of 2004-2018 in Finland 
Table 1 Unadjusted and adjusted odds ratios for risk factors for adverse outcomes in $24+0$ to $27+6$ weeks of gestational age fetuses in breech presentations 2004-2018 in Finland

\begin{tabular}{|c|c|c|c|c|}
\hline 24-27 weeks of gestation & $\begin{array}{l}\text { No adverse out- } \\
\text { comes }(N / \%) \\
N=172\end{array}$ & $\begin{array}{l}\text { Any adverse out- } \\
\text { come }(N / \%) \\
N=78\end{array}$ & Adjusted OR & $95 \%$ confidence limits \\
\hline Maternal age $<25$ & $5 / 2.9 \%$ & $4 / 5.1 \%$ & 2.04 & $0.48-8.66$ \\
\hline Maternal age $\geq 35$ & $48 / 27.9 \%$ & $23 / 29.5 \%$ & 1.31 & $0.65-2.58$ \\
\hline Maternal smoking & $30 / 17.4 \%$ & $13 / 16.7$ & 0.91 & $0.41-2.04$ \\
\hline Nulliparous & $76 / 44.2 \%$ & $42 / 53.8 \%$ & 1.82 & $0.93-3.54$ \\
\hline Multipara $\geq 3$ deliveries & $25 / 14.5 \%$ & $12 / 15.4 \%$ & 1.37 & $0.45-4.23$ \\
\hline $\mathrm{BMI} \geq 30$ & $25 / 14.5 \%$ & $11 / 14.1 \%$ & 1.20 & $0.41-3.50$ \\
\hline $\mathrm{BMI} \geq 35$ & $12 / 7.0 \%$ & $4 / 5.1 \%$ & 0.65 & $0.13-3.16$ \\
\hline History of induced abortion & $36 / 20.9 \%$ & $41 / 17.9 \%$ & 0.85 & $0.39-1.83$ \\
\hline History of miscarriage & $48 / 27.9 \%$ & $29 / 37.2 \%$ & 1.64 & $0.89-3.03$ \\
\hline History of cesarean section & $18 / 10.5 \%$ & $9 / 11.5 \%$ & 1.13 & $0.41-2.56$ \\
\hline Assisted reproduction technology & $7 / 4.1 \%$ & $0 / 0.0 \%$ & & \\
\hline Diabetes mellitus type I & $2 / 1.2 \%$ & $2 / 2.6 \%$ & 0.34 & $0.04-2.63$ \\
\hline Diabetes mellitus type II & $0 / 0.0 \%$ & $1 / 1.3 \%$ & & \\
\hline Gestational diabetes & $10 / 5.8 \%$ & $4 / 5.1 \%$ & 0.99 & $0.24-4.12$ \\
\hline Pre-eclampsia/high blood pressure & $20 / 11.6 \%$ & $4 / 5.1 \%$ & 0.49 & $0.15-1.58$ \\
\hline Oligohydramnios & $4 / 2.3 \%$ & $2 / 2.6 \%$ & 0.88 & $0.15-5.34$ \\
\hline Placenta previa & $3 / 1.7 \%$ & $1 / 1.3 \%$ & 0.54 & $0.05-5.99$ \\
\hline PPROM & $0 / 0.0 \%$ & $31 / 39.7 \%$ & 1.87 & $1.00-3.49$ \\
\hline Any congenital anomaly & $0 / 0.0 \%$ & $2 / 2.6 \%$ & 1.98 & $0.29-13.59$ \\
\hline Induced delivery & $47 / 27.3 \%$ & $1 / 1.3 \%$ & 0.50 & $0.04-5.97$ \\
\hline Epidural anesthesia in vaginal birth & $3 / 1.7 \%$ & $3 / 9.4 \%$ & 1.18 & $0.39-3.59$ \\
\hline Gestational age at delivery mean in days & $184 / 8$ & $179 / 8$ & & \\
\hline Fetal growth restriction (birth weight $<2 \mathrm{SD}$ ) & $0 / 0.0 \%$ & $1 / 1.3 \%$ & & \\
\hline Neonatal sex (female) & $87 / 50.6 \%$ & $34 / 43.6 \%$ & 0.75 & $0.42-1.34$ \\
\hline
\end{tabular}

$B M I$ body mass index, $P P R O M$ preterm premature rupture of membranes

aspiration of meconium [8, 22, 23]. Besides, previous studies have shown that a low amniotic fluid amount is linked with lower Apgar scores, a higher risk of neonatal acidosis and cesarean section as the mode of delivery due to fetal distress [22].

Fetal growth restriction in term is a well-known contraindication for vaginal breech delivery, since it is indisputably linked to severe adverse perinatal outcomes such as hypoxic injuries and even neonatal death $[8,21]$. Our results were coherent; fetal growth restriction $(<-2 \mathrm{SD} / \mathrm{IUGR})$ in planned vaginal breech delivery increased remarkably the risk for perinatal morbidity also in very preterm (sixfold) and in moderate to late preterm (12-fold) deliveries. Growth restricted fetuses might suffer more easily from distress during labor, and potential entrapment of the head during vaginal labor might increase the risks. Our study showed that smoking increased adverse outcomes in 33 to 36 weeks of gestation. Smoking is a major risk factor for intrauterine growth restriction and it is associated with obstetric complications such as placental abruption and placenta previa, as well as preterm birth itself $[24,25]$.

Maternal obesity was shown as a risk for neonatal health in very preterm breech deliveries. The risk for adverse outcome increased 32-fold, if women with a BMI above 35 attempted a trial of vaginal delivery among very preterm pregnancies. Antenatal and intrapartum obstetric complications, as well as perinatal morbidity and mortality, are known to be increased in obese mothers [7, 26, 27]. Maternal obesity is associated with preterm delivery itself, instrumental delivery, and cesarean section as a mode of birth $[26,27]$. Also, evaluation of fetal wellbeing might be more difficult in obese women [26]. Our personal opinion is that the massive obesity has an effect on the birth channel and that a very preterm fetus is not able to path through the birth channel smoothly, through excessive soft tissue resistance.

One of the essential findings of our study was that the induction of labor did not increase the risks in preterm breech deliveries (24-27 weeks of gestation: aOR 0.50, $p$ value $0.787,28-32$ weeks of gestation: aOR $2.13, p$ value 
Table 2 Unadjusted and adjusted odds ratios for risk factors for adverse outcomes in $28+0$ to $32+6$ weeks of gestational age fetuses in breech presentations 2004-2018 in Finland

\begin{tabular}{|c|c|c|c|c|}
\hline $28-32$ weeks of gestation & $\begin{array}{l}\text { No adverse out- } \\
\text { comes }(N / \%) \\
N=471\end{array}$ & $\begin{array}{l}\text { Any adverse out- } \\
\text { come }(N / \%) \\
N=47\end{array}$ & Adjusted OR & $95 \%$ confidence limits \\
\hline Maternal age $<25$ & $6 / 1.3 \%$ & $0 / 0.0 \%$ & & \\
\hline Maternal age $\geq 35$ & $123 / 26.1 \%$ & $12 / 25.5 \%$ & 1.02 & $0.46-2.22$ \\
\hline Maternal smoking & $80 / 17.0 \%$ & $6 / 12.8 \%$ & 0.54 & $0.20-1.45$ \\
\hline Nulliparous & $232 / 49.3 \%$ & $14 / 29.8 \%$ & 0.43 & $0.18-0.99$ \\
\hline Multipara $\geq 3$ deliveries & $61 / 13.0 \%$ & $9 / 19.1 \%$ & 1.31 & $0.39-4.44$ \\
\hline $\mathrm{BMI} \geq 30$ & $67 / 14.2 \%$ & $6 / 12.8 \%$ & 0.16 & $0.02-1.28$ \\
\hline $\mathrm{BMI} \geq 35$ & $18 / 3.8 \%$ & $5 / 10.6 \%$ & 32.19 & $2.97-348.65$ \\
\hline History of induced abortion & $72 / 15.3 \%$ & $10 / 21.3 \%$ & 1.60 & $0.69-3.71$ \\
\hline History of miscarriage & $111 / 23.6 \%$ & $14 / 29.8 \%$ & 1.03 & $0.48-2.18$ \\
\hline History of cesarean section & $72 / 15.3 \%$ & $15 / 31.9 \%$ & 1.79 & $0.79-4.06$ \\
\hline Assisted reproduction technology & $20 / 4.2 \%$ & $0 / 0.0 \%$ & & \\
\hline Diabetes mellitus type I & $24 / 5.1 \%$ & $1 / 2.1 \%$ & 2.53 & $0.27-24.17$ \\
\hline Diabetes mellitus type II & $3 / 0.6 \%$ & $0 / 0.0 \%$ & & \\
\hline Gestational diabetes & $43 / 9.1 \%$ & $3 / 6.4 \%$ & 1.66 & $0.40-6.89$ \\
\hline Pre-eclampsia/High blood pressure & $74 / 15.7 \%$ & $2 / 4.3 \%$ & 0.21 & $0.05-0.96$ \\
\hline Oligohydramnios & $12 / 2.5 \%$ & $7 / 14.9 \%$ & 6.50 & $2.00-21.11$ \\
\hline Placenta previa & $6 / 1.3 \%$ & $0 / 0.0 \%$ & 0.55 & $0.26-1.17$ \\
\hline PPROM & $152 / 32.3 \%$ & $12 / 25.5 \%$ & 0.55 & $0.26-1.17$ \\
\hline Any congenital anomaly & $19 / 4.0 \%$ & $8 / 17.0 \%$ & 4.50 & $1.56-12.96$ \\
\hline Induced delivery & $11 / 2.3 \%$ & $3 / 6.4 \%$ & 2.13 & $0.44-10.36$ \\
\hline Epidural anesthesia in vaginal birth & $25 / 26.3 \%$ & $4 / 25.0 \%$ & 1.48 & $0.47-4.63$ \\
\hline Gestational age at delivery mean in days & $216 / 10$ & $210 / 10$ & & \\
\hline Fetal growth restriction (birth weight $<2 \mathrm{SD}$ ) & $6 / 1.3 \%$ & $2 / 4.3 \%$ & 5.89 & $1.00-34.74$ \\
\hline Neonatal sex (female) & $218 / 46.3 \%$ & $17 / 36.2 \%$ & 0.74 & $0.37-1.48$ \\
\hline
\end{tabular}

$B M I$ body mass index, $P P R O M$ preterm premature rupture of membranes

$0.103,33-36$ weeks of gestation: aOR 1.38, $p$ value 0.105 ). Contrary findings were found in a recent meta-analysis (2018) as induction of term breech labor was found to increase the risk of perinatal morbidity and cesarean sections [28]. However, Macharey et al. found no association between induction of term breech labor and neonatal morbidity, but the rate of vaginal deliveries was remarkably lower if term breech labor was induced compared to the spontaneous breech deliveries [29]. Induction of term labor in breech presentation was established as safe as planned cesarean delivery also in observational prospective study 2019 [30].

Our results showed a connection between epidural anesthesia in vaginal breech labor and adverse outcomes in moderate to late preterm deliveries. Earlier studies have already shown a connection between epidural anesthesia and prolonged labor in term breech deliveries [31]. Furthermore, epidural anesthesia during labor is associated with increased augmentation with oxytocin and over twofold higher risk of adverse outcomes in term breech deliveries [8, 31]. It has been speculated whether adverse outcomes are due to the fact that epidural anesthesia is more used in prolonged labors or epidural anesthesia itself increases the duration of labor [8,31].

Interestingly, in our study pre-eclampsia or high blood pressure decreased the odds of adverse outcomes in very preterm breech deliveries. However, pre-eclampsia is a well-identified risk factor for maternal and neonatal mortality and morbidity [32]. Pre-eclampsia is associated with intrauterine growth restriction and congenital anomalies [32-34], in which both conditions increased the adverse perinatal outcomes in our study among very preterm deliveries. Our contradictory results might be explained by the fact that the small number of cases may not have had enough power to detect differences between the groups. Besides, maternal obstetric risk factors such as pre-eclampsia or high blood pressure may be considered as a contraindication for vaginal delivery and thus these women have more often a planned cesarean section 
Table 3 Unadjusted and adjusted odds ratios for risk factors for adverse outcomes in $33+0$ to $36+6$ weeks of gestational age fetuses in breech presentations 2004-2018 in Finland

\begin{tabular}{|c|c|c|c|c|}
\hline 33-36 weeks of gestation & $\begin{array}{l}\text { No adverse out- } \\
\text { comes }(N / \%) \\
N=1497\end{array}$ & $\begin{array}{l}\text { Any adverse out- } \\
\text { come }(N / \%) \\
N=47\end{array}$ & Adjusted OR & $95 \%$ confidence limits \\
\hline Maternal age $<25$ & $31 / 2.1 \%$ & $1 / 2.1 \%$ & 0.49 & $0.05-4.74$ \\
\hline Maternal age $\geq 35$ & $362 / 24.2 \%$ & $11 / 23.4 \%$ & 0.94 & $0.44-2.02$ \\
\hline Maternal smoking & $227 / 15.2 \%$ & $14 / 29.8 \%$ & 2.29 & $1.12-4.72$ \\
\hline Nulliparous & $872 / 58.2 \%$ & $22 / 46.8 \%$ & 0.87 & $0.42-1.83$ \\
\hline Multipara $\geq 3$ deliveries & $116 / 7.7 \%$ & $7 / 14.9 \%$ & 1.42 & $0.43-4.68$ \\
\hline $\mathrm{BMI} \geq 30$ & $155 / 10.4 \%$ & $8 / 17.0 \%$ & 0.92 & $0.25-3.35$ \\
\hline $\mathrm{BMI} \geq 35$ & $57 / 3.8 \%$ & $5 / 10.6 \%$ & 2.88 & $0.54-15.19$ \\
\hline History of induced abortion & $174 / 11.6 \%$ & $7 / 14.9 \%$ & 0.98 & $0.39-2.44$ \\
\hline History of miscarriage & $355 / 23.7 \%$ & $10 / 21.3 \%$ & 0.69 & $0.31-1.51$ \\
\hline History of cesarean section & $172 / 11.5 \%$ & $8 / 17.0 \%$ & 1.82 & $0.71-4.63$ \\
\hline Assisted reproduction technology & $61 / 4.1 \%$ & $0 / 0.0 \%$ & & \\
\hline Diabetes mellitus type I & $24 / 1.6 \%$ & $1 / 2.1 \%$ & 0.43 & $0.05-3.56$ \\
\hline Diabetes mellitus type II & $3 / 0.2 \%$ & $1 / 2.1 \%$ & 0.11 & $0.01-1.39$ \\
\hline Gestational diabetes & $153 / 10.2 \%$ & $5 / 10.6 \%$ & 0.99 & $0.36-2.77$ \\
\hline Pre-eclampsia/High blood pressure & $106 / 7.1 \%$ & $1 / 2.1 \%$ & 0.20 & $0.03-1.60$ \\
\hline Oligohydramnios & $23 / 1.5 \%$ & $8 / 17.0 \%$ & 19.06 & $7.15-50.85$ \\
\hline Placenta previa & $20 / 1.3 \%$ & $1 / 2.1 \%$ & 2.13 & $0.26-17.41$ \\
\hline PPROM & $406 / 27.1 \%$ & $9 / 19.1 \%$ & 0.73 & $0.33-1.61$ \\
\hline Any congenital anomaly & $111 / 7.4 \%$ & $4 / 8.5 \%$ & 0.89 & $0.27-2.99$ \\
\hline Induced delivery & $123 / 8.2 \%$ & $7 / 14.9 \%$ & 1.38 & $0.51-3.71$ \\
\hline Epidural anesthesia in vaginal birth & $250 / 42.6 \%$ & $15 / 55.6 \%$ & 2.44 & $1.19-5.01$ \\
\hline Gestational age at delivery mean in days & $246 / 9$ & $249 / 7$ & & \\
\hline Fetal growth restriction (birth weight $<2 \mathrm{SD}$ ) & $11 / 0.7 \%$ & $3 / 6.4 \%$ & 12.27 & $2.81-53.66$ \\
\hline Neonatal sex (female) & $703 / 47.0 \%$ & $26 / 55.3 \%$ & 1.39 & $0.74-2.62$ \\
\hline
\end{tabular}

$B M I$ body mass index, $P P R O M$ preterm premature rupture of membranes

as mode of delivery. These circumstances might cause bias in the results [35].

Other authors have shown primiparous women to have more adverse perinatal outcomes [36]. Furthermore, primiparity is linked to low birth weight in term pregnancies [37], and in our results, fetal growth restriction in preterm breech deliveries seemed to increase the risks. Nevertheless, primiparity in preterm breech deliveries was not found as a risk for perinatal morbidity in our study, and in contrary, primiparity appeared as a protective factor in very preterm vaginal breech delivery. This finding may partly be explained that the mode of birth is more likely primary cesarean section in nulliparous women when the fetus is in a breech position.

Congenital anomalies in term breech pregnancies are known risks for perinatal morbidity and mortality [7, 9, 38 ], and our study showed similar results among very preterm breech fetuses. In addition, other studies have linked oligohydramnios, fetal growth restriction, maternal obesity, and high blood pressure to increased congenital anomalies [24, 27, 39], and as shown before, these factors were risks for adverse outcomes in our study as well. However, in many cases of severe congenital anomalies, vaginal delivery is favorable also in breech deliveries to minimize maternal morbidity [40].

In extremely preterm breech deliveries over $30 \%$ had adverse outcomes. In this group the only risk factor found for adverse outcomes was PPROM. The extremely preterm delivery itself is a major risk for short-term neonatal morbidity [41], and this fact may be the reason why we could not identify more risk factors. Sephton S showed PPROM to be associated with a significant risk of neonatal morbidity partly due to infections and placental abruptions [42-44]. Preterm fetuses with PPROM and born vaginally may not tolerate the contractions during labor or the compression when descending in the birth canal [45]. Preterm breech deliveries complicated with PPROM may also have more difficulties with the delivery of the aftercoming head [46]. In a Cochrane review (2017) Bond and colleagues pointed out that despite PPROM before 37 weeks' gestation and without contraindications, expectant management 
in careful evaluation is associated with good neonatal outcomes [47].

Our study offers essential information about the risks of adverse outcomes in preterm breech deliveries. This is the first study that was able to identify risk factors for adverse neonatal outcomes in planned vaginal preterm breech delivery. Understanding the risks for adverse outcomes is essential for the decision-making on the mode of delivery when treating preterm breech deliveries. Obstetricians can now select for preterm breech presentation those women who should give birth by cesarean section in any case. Some of the risk factors like oligohydramnios, congenital anomalies, and fetal growth restriction were similar as in planned vaginal breech delivery at term $[8,21]$, but others, like severe maternal obesity and PPROM, were not known as risk factors for breech deliveries overall. This study is a unique population-based case-control study of the subject and offers valuable information for decision-making when treating preterm breech deliveries.

There are, however, few limitations in our study. Designed as a retrospective trial, we are exposed to the possibility of a typical bias of retrospective case-control studies. Additionally, data were restricted to the information of the data bank. In a few risk factors, we might have lacked statistical power to detect the risks of adverse outcomes, as there were only a few patients in the group. Nevertheless, our study was population-based and included over 2300 vaginal preterm breech deliveries from 14 years. Because there are no private birth hospitals in Finland, the treatment of the deliveries are homogenous and comparative.

\section{Conclusion}

We recommend a planned cesarean section for women with severe maternal obesity (BMI > 35), oligohydramnios, or fetal growth restriction in very preterm breech deliveries $(28+0$ to $32+6$ weeks) and for women with oligohydramnios or a fetus with fetal growth restriction $(<2 \mathrm{SD})$ in moderate to late preterm breech deliveries $(33+0$ to $36+6$ weeks).

Acknowledgements Open access funding provided by University of Helsinki including Helsinki University Central Hospital.

Author contribution AT: Project development, manuscript writing. SH: Project development, manuscript editing. MG: Data management and analysis, manuscript editing. GM: Project development, manuscript editing. All authors read and approved the final manuscript.

Funding This study was funded by Helsinki University Hospital Research Grants.

Data availability The Finnish register data have been given for this specific study, and the data cannot be shared without authorization from the register keepers. More information on the authorization application to researchers who meet the criteria for access to confidential data can be found at Findata, the Health and Social Data Permit Authority: https://www.findata.fi/en/.

\section{Compliance with ethical standards}

Conflict of interest The author A. Toijonen declares that she has no conflict of interest. The author S. Heinonen declares that he has no conflict of interest. The author M. Gissler declares that he has no conflict of interest. The author G. Macharey declares that he has no conflict of interest.

Ethical approval This article does not contain any studies with human participants performed by any of the authors.

Informed consent The register keeping organizations gave their permission to use their confidential health data in this study. No registered persons were contacted and thus, no consent for participant was needed. The Finnish Institute for Health and Welfare authorized to use the data (reference number THL/652/5.05.00/2017).

Code availability SAS custom code cannot be shared publicly, but it is available on request from Mika Gissler (mika.gissler@thl.fi).

Open Access This article is licensed under a Creative Commons Attribution 4.0 International License, which permits use, sharing, adaptation, distribution and reproduction in any medium or format, as long as you give appropriate credit to the original author(s) and the source, provide a link to the Creative Commons licence, and indicate if changes were made. The images or other third party material in this article are included in the article's Creative Commons licence, unless indicated otherwise in a credit line to the material. If material is not included in the article's Creative Commons licence and your intended use is not permitted by statutory regulation or exceeds the permitted use, you will need to obtain permission directly from the copyright holder. To view a copy of this licence, visit http://creativecommons.org/licenses/by/4.0/.

\section{References}

1. Albrechtsen S, Rasmussen S, Dalaker K, Irgens LM (1998) The occurrence of breech presentation in Norway 1967-1994. Acta Obstet Gynecol Scand 77(4):410-415

2. Hickok DE, Gordon DC, Milberg JA, Williams MA, Daling JR (1992) The frequency of breech presentation by gestational age at birth: a large population-based study. Am J Obstet Gynecol 166(3):851-852

3. Zsirai L, Csákány GM, Vargha P, Fülöp V, Tabák ÁG (2016) Breech presentation: its predictors and consequences. An analysis of the Hungarian Tauffer Obstetric Database (1996-2011). Acta Obstet Gynecol Scand 95(3):347-354

4. Cammu H, Dony N, Martens G, Colman R (2014) Common determinants of breech presentation at birth in singletons: a populationbased study. Eur J Obstet Gynecol Reprod Biol 177:106-109

5. Hannah ME, Hannah WJ, Hewson SA, Hodnett ED, Saigal S, Willan AR (2000) Planned caesarean section versus planned vaginal birth for breech presentation at term: a randomised multicentre trial. Lancet 356(9239): 1375-1383

6. Fruscalzo A, Londero AP, Salvador S, Bertozzi S, Biasioli A, Della Martina M et al (2014) New and old predictive factors for breech presentation: our experience in 14433 singleton 
pregnancies and a literature review. J Matern Neonatal Med 27(2):167-172

7. Gardosi J, Madurasinghe V, Williams M, Malik A, Francis A (2013) Maternal and fetal risk factors for stillbirth: population based study. BMJ 346:f108

8. Macharey G, Gissler M, Ulander VM, Rahkonen L, VäisänenTommiska M, Nuutila M et al (2017) Risk factors associated with adverse perinatal outcome in planned vaginal breech labors at term: a retrospective population-based case-control study. BMC Pregnancy Childbirth 17(1):93

9. Fretts R (2010) Stillbirth epidemiology, risk factors, and opportunities for stillbirth prevention. Clin Obstet Gynecol 53(3):588-596

10. Whyte H, Hannah ME, Saigal S, Hannah WJ, Hewson S, Amankwah $\mathrm{K}$ et al (2004) Outcomes of children at 2 years after planned cesarean birth versus planned vaginal birth for breech presentation at term: The international randomized Term Breech Trial. Am J Obstet Gynecol 191(3):864-871

11. MacHarey G, Ulander VM, Heinonen S, Kostev K, Nuutila M, Vaïsänen-Tommiska M (2017) Risk factors and outcomes in "wellselected" vaginal breech deliveries: a retrospective observational study. J Perinat Med 45(3):291-297

12. Macharey G (2018) Breech presentation and delivery in singleton term pregnancies in Finland. Medical Faculty of the University of Helsinki, vol 1, pp 1-179. ISBN: 978-951-51-4023-4

13. Azria E, Le Meaux JP, Khoshnood B, Alexander S, Subtil D, Goffinet F (2012) Factors associated with adverse perinatal outcomes for term breech fetuses with planned vaginal delivery. Am J Obstet Gynecol 207(4):285-e1

14. Goffinet F, Carayol M, Foidart JM, Alexander S, Uzan S, Subtil D et al (2006) Is planned vaginal delivery for breech presentation at term still an option? Results of an observational prospective survey in France and Belgium. Am J Obstet Gynecol 194(4):1002-1011

15. Macharey G, Väisänen-Tommiska M, Gissler M, Ulander VM, Rahkonen L, Nuutila M et al (2018) Neurodevelopmental outcome at the age of 4 years according to the planned mode of delivery in term breech presentation: a nationwide, population-based record linkage study. J Perinat Med 46(3):333-339

16. Management of breech presentation: green-top guideline No. $20 \mathrm{~b}$. BJOG An Int J Obstet Gynaecol (2017)

17. Azria E, Kayem G, Langer B, Marchand-Martin L, Marret S, Fresson $\mathbf{J}$ et al (2016) Neonatal mortality and long-term outcome of infants born between 27 and 32 weeks of gestational age in breech presentation: the EPIPAGE cohort study. PLoS One 11(1):e0145768

18. Bergenhenegouwen LA, Meertens LJE, Schaaf J, Nijhuis JG, Mol BW, Kok M et al (2014) Vaginal delivery versus caesarean section in preterm breech delivery: a systematic review. Eur J Obstet Gynecol Reprod Biol 172:1-6

19. Demirci O, Tuğrul AS, Turgut A, Ceylan Ş, Eren S (2012) Pregnancy outcomes by mode of delivery among breech births. Arch Gynecol Obstet 285(2):297-303

20. Biswas A, Su LL, Mattar C (2013) Caesarean section for preterm birth and breech presentation and twin pregnancies. Best Pract Res Clin Obstet Gynaecol 27(2):209-219

21. Su M, McLeod L, Ross S, Willan A, Hannah WJ, Hutton E et al (2003) Factors associated with adverse perinatal outcome in the Term Breech Trial. Am J Obstet Gynecol 189(3):740-745

22. Chauhan SP, Sanderson M, Hendrix NW, Magann EF, Devoe LD (1999) Perinatal outcome and amniotic fluid index in the antepartum and intrapartum periods: A meta-analysis. Am J Obstet Gynecol 181(6):1473-1478

23. Lai J, Nowlan NC, Vaidyanathan R, Shaw CJ, Lees CC (2016) Fetal movements as a predictor of health. Acta Obstet Gynecol Scand 95(9):968-975

24. Suhag A, Berghella V (2013) Intrauterine growth restriction (IUGR): etiology and diagnosis. Curr Obstet Gynecol Rep 2(2):102-111
25. Delpisheh A, Brabin L, Brabin BJ (2006) Pregnancy, smoking and birth outcomes. Women's Health 2(3):389-403

26. Chodankar R, Middleton G, Lim C, Mahmood T (2018) Obesity in pregnancy. Obstet Gynaecol Reprod Med 113(10):1117-1125

27. Marchi J, Berg M, Dencker A, Olander EK, Begley C (2015) Risks associated with obesity in pregnancy, for the mother and baby: a systematic review of reviews. Obes Rev 16(8):621-638

28. Sun W, Liu F, Liu S, Gratton SM, El-Chaar D, Wen SW et al (2018) Comparison of outcomes between induction of labor and spontaneous labor for term breech — a systemic review and meta analysis. Eur J Obstet Gynecol Reprod Biol 222:155-160

29. Macharey G, Ulander V-M, Heinonen S, Kostev K, Nuutila M, Väisänen-Tommiska M (2016) Induction of labor in breech presentations at term: a retrospective observational study. Arch Gynecol Obstet 293(3):549-555. https://doi.org/10.1007/s00404-015-3853-4

30. Gaillard T, Girault A, Alexander S, Goffinet F, Le Ray C (2019) Is induction of labor a reasonable option for breech presentation? Acta Obstet Gynecol Scand 98(7):885-893

31. Chadha YC, Mahmood TA, Dick MJ, Smith NC, Campbell DM, Templeton A (1992) Breech delivery and epidural analgesia. BJOG An Int J Obstet Gynaecol 99(2):96-100

32. Backes CH, Markham K, Moorehead P, Cordero L, Nankervis CA, Giannone PJ (2011) Maternal preeclampsia and neonatal outcomes. J Pregnancy 2011:214365

33. Villar J, Carroli G, Wojdyla D, Abalos E, Giordano D, Ba' aqeel H et al (2006) Preeclampsia, gestational hypertension and intrauterine growth restriction, related or independent conditions? Am J Obstet Gynecol 194(4):921-931

34. Ødegård RA, Vatten LJ, Nilsen ST, Salvesen KÅ, Austgulen R (2000) Preeclampsia and fetal growth. Obstet Gynecol 96(6):950-955

35. Alanis MC, Robinson CJ, Hulsey TC, Ebeling M, Johnson DD (2008) Early-onset severe preeclampsia: induction of labor vs elective cesarean delivery and neonatal outcomes. Am J Obstet Gynecol 199(3):262-e1

36. Bai J, Wong FWS, Bauman A, Mohsin M (2002) Parity and pregnancy outcomes. Am J Obstet Gynecol 186(2):274-278

37. Shah PS (2010) Parity and low birth weight and preterm birth: a systematic review and meta-analyses. Acta Obstetricia et Gynecologica Scandinavica 89(7):862-875

38. Newtonraj A, Kaur M, Gupta M, Kumar R (2017) Level, causes, and risk factors of stillbirth: a population-based case control study from Chandigarh, India. BMC Pregnancy Childbirth 17(1):371

39. Chhabra S, Dargan R, Bawaskar R (2007) Oligohydramnios: a potential marker for serious obstetric complications. J Obstet Gynaecol (Lahore) 27(7):680-683

40. Anteby EY, Yagel S (2003) Route of delivery of fetuses with structural anomalies. Eur J Obstet Gynecol Reprod Biol 106(1):5-9

41. Patel RM (2016) Short- and long-term outcomes for extremely preterm infants. Am J Perinatol 33(3):318

42. Sephton V, Redfern A, Roberts D (2011) Maternal and neonatal outcomes in preterm prelabour rupture of membranes between 24 and 34 weeks gestation. Arch Dis Child Fetal Neonatal Ed 96(Suppl 1):Fa113

43. Tikkanen M (2011) Placental abruption: epidemiology, risk factors and consequences. Acta Obstetricia et Gynecologica Scandinavica 90(2):140-149

44. Schmitz T, Sentilhes L, Lorthe E, Gallot D, Madar H, Doret-Dion $\mathrm{M}$ et al (2019) Preterm premature rupture of the membranes: Guidelines for clinical practice from the French College of Gynaecologists and Obstetricians (CNGOF). Eur J Obstet Gynecol Reprod Biol 236:1-6

45. Jiang HL, Lu C, Wang XX, Wang X, Zhang WY (2020) Cesarean section does not affect neonatal outcomes of pregnancies complicated with preterm premature rupture of membranes. Chin Med J (Engl) 133(1):25 
46. Lorthe E, Sentilhes L, Quere M, Lebeaux C, Winer N, Torchin H et al (2019) Planned delivery route of preterm breech singletons, and neonatal and 2-year outcomes: a population-based cohort study. BJOG Int J Obstet Gynaecol 126(1):73-82

47. Bond DM, Middleton P, Levett KM, van der Ham DP, Crowther CA, Buchanan SL et al (2017) Planned early birth versus expectant management for women with preterm prelabour rupture of membranes prior to 37 weeks' gestation for improving pregnancy outcome. Cochrane Database Syst Rev 3(3):CD004735
Publisher's Note Springer Nature remains neutral with regard to jurisdictional claims in published maps and institutional affiliations. 